Didáctica. Lengua y literatura

ISSN-e: 1988-2548

https://dx.doi.org/10.5209/dida.65946

\title{
Estudio de casos sobre el hábito de lectura entre los niños de 0 a 12 años en Extremadura
}

\author{
José Soto Vázquez ${ }^{1}$; M $^{\mathrm{a}}$ Esther Cordero Aparicio² ${ }^{2}$ Francisco Javier Jaraíz Cabanillas $^{3}$
}

Fecha de recepción: 12-07-2017 / Fecha de aceptación: 23-11-2018

Resumen. En el trabajo tratamos de articular dos ejes fundamentales acerca de la lectura en el ámbito rural, con niños de entre 0 y 12 años de un municipio de la provincia de Cáceres (Arroyo de la Luz). De un lado se ha realizado el vaciado de la base de datos de la biblioteca municipal cruzando la información entre la población del municipio, el número de socios y el préstamo de libros desde 2004 a 2016. Los resultados obtenidos se han mostrado mediante gráficos, atendiendo a la edad y sexo de los sujetos. En segundo lugar, se ha efectuado un trabajo de encuestas en los centros escolares de Educación Primaria, de modo que se contrasten los datos objetivos con la percepción que tienen los jóvenes de sus lecturas y hábitos culturales. Como resultados más relevantes se confirma un mayor índice lector entre las niñas en todas las edades; igualmente, los géneros más demandados son los de aventuras y acción; al tiempo que apreciamos un paulatino descenso de los hábitos lectores en la franja de edad analizada a partir de los seis años.

Palabras claves: hábitos de lectura; Educación Primaria; bibliotecas públicas; encuestas; Extremadura.

\section{[en] Research about reading habits among children of ages between 0-12 in Extremadura}

\begin{abstract}
In this project, we have tried to bring together two essential ideas about reading in the rural field, with children of ages between 0-12 from a village in the Province of Extremadura called "Arroyo de la Luz". In the first place, the database of the public library have been got mixing the information between the village's people, the number of fellows and the books for borrowing from 2004 to 2016. The results obtained have been shown by means of graphics paying attention to the age and sex of the people. In the second place, a project of surveys has been carried out in Primary Schools so that the impartial data can be contrasted with the perception that young people have of their reading and cultural habits. The most relevant results confirm a higher reading index among girls of all ages; likewise, the genres most in demand are those of adventure and action; while we appreciate a gradual decline in reading habits in the age group analysed after six years.
\end{abstract}

Keywords: Reading habits; Elementary School; public library; surveys; Extremadura.

1 Departamento de Didáctica de las Ciencias Sociales, Lenguas y Literaturas

Universidad de Extremadura

jsoto@unex.es

2 Biblioteca municipal de Arroyo de la Luz

mcorderofa@alumnos.unex.es

3 Departamento de Didáctica de las Ciencias Sociales, Lenguas y Literaturas

Universidad de Extremadura

jfjaraiz@unex.es 


\section{[fr] Étude de cas sur les habitudes de lecture chez les enfants de 0-12 ans en Estrémadure}

Resume: Au travail, nous essayons d'articuler deux axes principaux sur la lecture dans les zones rurales, avec des enfants de 0 à 12 ans d'une municipalité dans la province de Cáceres (Arroyo de la Luz). D'un côté a été fait vider la base de données sur l'information bibliothèque municipale au sein de la population de la commune, le nombre de partenaires et de livres d'emprunt de 2004 à 2016. Les résultats obtenus sont présentés par des graphiques, assistant l'âge et le sexe des sujets. En second lieu, le travail a été effectué des enquêtes dans les écoles de l'enseignement primaire, de sorte que le contraste de données objectives à la perception que les jeunes ont leurs lectures et les habitudes culturelles. Les résultats les plus pertinents confirment un indice de lecture plus élevé chez les filles de tous les âges; de même, les genres les plus demandés sont ceux d'aventure et d'action; alors que nous apprécions une baisse progressive des habitudes de lecture dans le groupe d'âge analysé après six ans.

Mots-clés: es habitudes de lecture; Éducation primaire; bibliothèques publiques; enquêtes; Estremadura.

Sumario. 1. Introducción. Encuesta de hábitos y prácticas culturales en España y Extremadura. 2. Nuestro estudio. 3. Estudio sobre los hábitos lectores en la biblioteca municipal. 3.1. Características socio-demográficas de Arroyo de la Luz. 3.2. Nacimientos/lectores infantiles de la biblioteca municipal. Resultados de esta interrelación. Gráficos de libros leídos entre 2004 y 2016 por los nacidos entre 2004 y 2011. Libros leídos por los niños nacidos en 2004 en la biblioteca municipal. Libros leídos por los niños nacidos en 2010 en la biblioteca municipal. 4. Encuesta del alumnado de Educación Primaria. Análisis de los gráficos resultantes. 5. Conclusiones. 6. Agradecimientos. 7. Bibliografía

Cómo citar: Soto Vázquez, J; Cordero Aparicio, Ma E.; Jaraíz Cabanillas, F. J. (2019). Estudio de casos sobre el hábito de lectura entre los niños de 0 a 12 años en Extremadura, Didáctica. Lengua y literatura, $31,147-170$.

\section{Introducción}

La lectura tiene una gran importancia en el desarrollo del niño y en el aprendizaje escolar. Se considera una herramienta imprescindible para el desarrollo de las competencias clave en el sistema educativo, tal y como se insiste en la Orden ECD/65/2015 (2015). Su práctica ayuda a que los jóvenes adquieran cada vez más vocabulario (Schmitt y Baumann, 1990; Villegas, 2010), con la intención de que sus conversaciones sean más estructuradas. De este modo, conseguir un buen hábito lector proporciona valores que les serán muy útiles a lo largo de su vida (Rubio, 2007; Bernabeu et al., 2011). Por ello, la mayoría de las actividades escolares parten de la lectura, ya que la competencia en comunicación lingüística se refiere a la habilidad para utilizar la lengua, expresar ideas e interactuar con otras personas de manera oral o escrita (Molina, 2015). La interrelación entre biblioteca y escuela (UNESCO, 2000; MECD, 2011: 12) ayuda a comprender este proceso, ya que en esta última es donde nos enseñan a leer, pero ninguna otra institución velará a lo largo de nuestra vida por garantizar nuestro derecho de acceso a la lectura como la biblioteca.

El concepto generalista de hábito esbozado por la RAE como la repetición de actos es matizado por Lomas (2002: 167) respecto a la lectura:

Los niños de 8, 9,10 y 11 años se encuentran en el mejor momento para el desarrollo de hábitos lectores. A estas edades vuestros hijos ya han adquirido las destrezas básicas de la mecánica lectora, ya han interiorizado el código de lectura y lo aplican de manera automática, y poseen una comprensión aceptable del texto. 
Es decir, están en condiciones de gozar leyendo. Es el momento de conseguir la afición por la lectura.

Como todo hábito, se modela poco a poco y es muy positivo que se fomente durante la infancia. Debemos hacer que la selección de un libro antes de ir a dormir o en su tiempo libre sea tan placentero que sienta la necesidad de que se convierta en una costumbre (Martín, 2012; Bernstein, 1975). Si bien, dicho hábito ha de contener prácticas lúdicas y recreativas que acompañen su adquisición (Pennac, 1993: 91; Lomas, 2002: 78 y 109; Shedlock, 2008: 254). No es bueno presionarlos, sino acompasarnos a su ritmo y que, cuando lean, lo hagan con ilusión. Es cierto que esta práctica ha cambiado actualmente, ya que, por ejemplo, los más pequeños ojean libros por puro placer, les gusta pasar sus páginas, visualizar sus ilustraciones y abandonarse, de manera inevitable, a cada una de las historias que cuentan. El formato se ha modificado hoy día a favor de la lectura en pantallas (Martos y Campos [Coords.], 2013), se amplían así las posibilidades lectoras tradicionales (Cervera, 1988: 214-215; Cerrillo, 2005), aunque sabemos que el libro en papel es el formato más usual entre los jóvenes (Viñao, 2002: 356 y ss.; Peronard, 2007), por lo que nos centraremos en este soporte en nuestro estudio.

Dado que la lectura literaria es una actividad que nos acompaña a lo largo de la vida (Godoy 2012: 60-62), en la que se mantiene un diálogo con el narrador/autor (Atwood, 1984: 7), son necesarios trabajos parciales que permitan conocer como se lleva a cabo este proceso por los niños en la actualidad, tanto en el ámbito escolar (Colomer y Camps, 1990: 36), como en su contexto sociocultural más cercano (Gil, 2009; Serna et al., 2017), con el objetivo de determinar de qué manera contribuye este hecho a su mejora en la comprensión lectora futura (García, 2011: 91-93).

\section{Encuesta de hábitos y prácticas culturales en España y Extremadura}

El conjunto de trabajos estadísticos actuales sobre este campo ha sido muy numeroso y diverso, bien por estudios regionales sobre la Educación Secundaria (Olaziregi, 2000; Muñoz y Hernández, 2011); la lectura en red (MECD, 2013-2014); la participación familiar (Gil, 2009; MECD, 2014); o el sector editorial (MECD, 2016; Asociación de las Cámaras del libro en España, 2016). Investigaciones que se completan en La lectura en España (Millán [Coord], 2017), junto a un largo etcétera que sería muy extenso de recopilar en estas líneas.

Nos interesan particularmente dos trabajos previos en lo que concierne a los estudios estadísticos sobre la adquisición del hábito lector, que serán el punto de partida de esta investigación: de un lado Hábitos de lectura y compra de libros en Extremadura [14 a 24 años] (Fundación Germán Sánchez Ruipérez, 2007) y de otro la Encuesta de Hábitos y Prácticas Culturales en España 2014/2015 (MECD, 2016). La Encuesta supone la estadística oficial de carácter cuatrienal que forma parte del Plan Estadístico Nacional y que constituye un análisis pormenorizado sobre los hábitos y prácticas, en definitiva, el consumo de la oferta cultural de los españoles. A la vez que, particularmente para Extremadura, partiremos del estudio realizado por la Fundación Germán Sánchez Ruipérez (2007), dentro de las iniciativas del Observatorio del Libro y la Lectura en la región. Debemos señalar que los grupos de edad estudiados en ambas ocasiones no se correspondan con los que hemos fijado para este trabajo, si bien son las investigaciones de mayor calado a las que podemos acudir hasta la fecha. 
El primero realizó encuestas a 16000 personas de 15 años en adelante. Mientras que el segundo contó con 600 encuestas realizadas en Extremadura (atendiendo a la edad, sexo y tipo de hábitat, según el número de habitantes) a lectores entre 14 y 24 años, comparándolos con los registros nacionales. Pese a la distancia temporal entre ambos, coinciden en algunas conclusiones generales, como son el reconocimiento de prácticas lectoras habituales (en Extremadura el 80\% declaraba que le gustaría leer más y el 68,9\% que lo hacía por entretenimiento; a nivel nacional el 62,2\% reconocía como su práctica habitual cultural más frecuente la lectura). Igualmente, en ambos casos se confirmaba una mayor frecuencia lectora entre las mujeres frente a los hombres, quienes además acuden con más asiduidad a bibliotecas públicas para consultas de todo tipo; o que en ambos casos, la población con menor edad es la que mayor participación tiene en las actividades culturales, hecho en el que influye la formación académica individual y de sus familiares.

\section{Nuestro estudio}

A tenor de lo descrito, considerábamos necesario actualizar las cifras existentes (que databan de 2007 en el caso extremeño, con un total de 273 encuestas para localidades entre 5000 y 10000 habitantes, a jóvenes entre 14 y 24 años de edad). De este modo, nos marcamos como reto disponer de indicadores relativos al hábito de lectura de los niños de Educación Primaria y fijamos nuestro objetivo en un municipio concreto. No obstante, siendo conscientes de las limitaciones que suponen la focalización específica de un trabajo tan local (sin la pretensión de extrapolarlo a una población mayor), entendemos que sin estos estudios de casos concretos no es posible ofrecer resultados globales de mayor precisión. Por ello, este proceso se ha realizado en Arroyo de la Luz, una localidad de unos 5000 habitantes de la provincia de Cáceres, en la que hemos registrado el hábito lector de sus niños entre 0 y 12 años, con el fin de conocer su frecuencia y sus prácticas lectoras a lo largo del tiempo, atendiendo a la etapa educativa, edad y sexo de los nacidos entre 2004 y 2011.

Para ello hemos aplicado dos técnicas de trabajo diferentes. Primeramente, hemos realizado un vaciado de la base de datos de la biblioteca municipal y hemos contrastado el número de nacidos en la localidad con el de los lectores registrados en la misma. En segundo lugar, hemos creado un estudio estadístico de las lecturas del conjunto de socios de la biblioteca entre esos años (la amplia mayoría de la población, 284 niños), tomando como referencia su préstamo bibliotecario. El siguiente paso ha sido la creación de gráficos que permitan visualizar esos resultados, tanto de carácter global como mediante el análisis particular de los niños nacidos en años concretos (2004 y 2010), para hacer un estudio comparativo entre dos conjuntos distintos. La información que obtuvimos nos permitió establecer un diagnóstico de la situación actual de estos indicadores lectores en la localidad y conocer su evolución a lo largo del tiempo.

Paralelamente hemos pasado cincuenta encuestas anónimas [ver imagen 1] (para lo cual realizamos un análisis de las características sociodemográficas de sus habitantes que permita considerar el número de encuestas necesarias para obtener datos fiables, mediante un muestreo estratificado) a niños de Educación Primaria (Morales, 2012: 3). El cuestionario se componía de quince preguntas que inciden sobre el consumo de libros principalmente. Están orientadas a recabar información sobre frecuencia, afición y criterios de lectura del sujeto encuestado. La finalidad es saber cuáles son los principales gustos lectores de los niños, al igual que nos permite saber qué tiempo le 
dedican o cuál sería su hábito lector. Los resultados obtenidos los hemos plasmado en diferentes gráficos en los que hemos explicado cada una de las preguntas de manera individual. De este modo queríamos contrastar la percepción que los lectores tenían frente a sus prácticas lectoras analizadas en la biblioteca municipal.
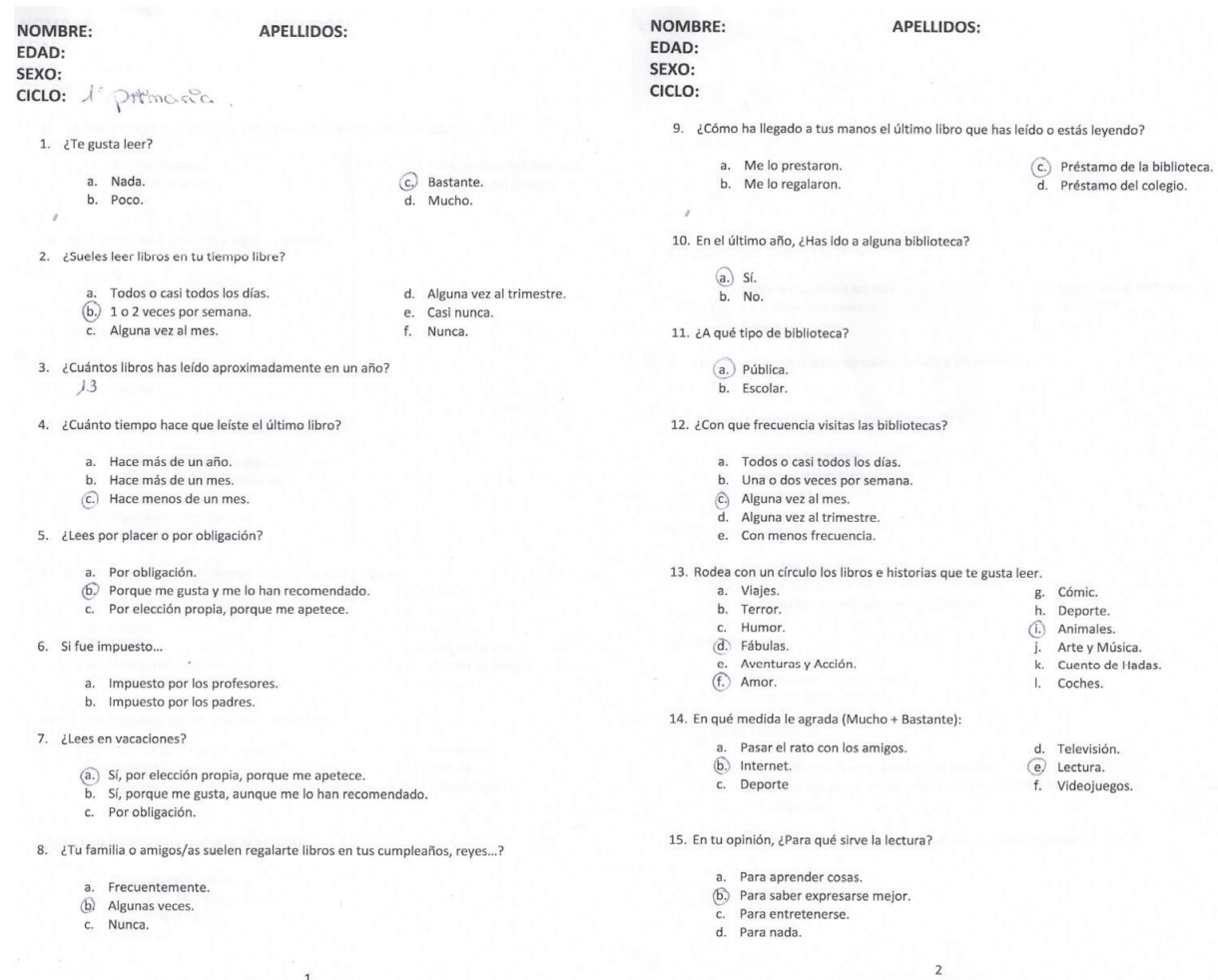

Imagen 1. Ejemplo de encuesta realizada.

Fuente: elaboración propia.

\section{Estudio sobre los hábitos lectores en la biblioteca municipal}

\subsection{Características socio-demográficas de Arroyo de la Luz}

Conocer la estructura demográfica de la población estudiada es fundamental para contextualizar y entender sus hábitos de lectura, ya que estos factores son decisivos en los ciudadanos. De estas variables, la edad y el sexo son de las más determinantes (Olaziregi, 2000: 82) ya que reflejan mayores diferencias (prelectores, primeros lectores, lectores consolidados), disminuyendo el porcentaje a medida que aumenta la edad biológica. La distribución demográfica en Extremadura no es uniforme, pues hay una gran dispersión poblacional en municipios con pocos habitantes, según se desprende en el gráfico 1 sobre el grado de ruralidad de sus pueblos. Como han manifestado Nieto y Gurría (2005), las poblaciones rurales van perdiendo población y servicios desde hace años $y$, al igual que se han estudiado variantes socioeconómicas para entender este problema, es necesaria la investigación de aspectos culturales y 
educativos que se ocupen de entidades menores, ya que las poblaciones por debajo de los 10000 habitantes suponen en Extremadura mas del 96\% de los municipios de la región, con una dispersión de población que hace que, sin embargo, el 50\% de sus habitantes viva en localidades con más de 10000 vecinos.

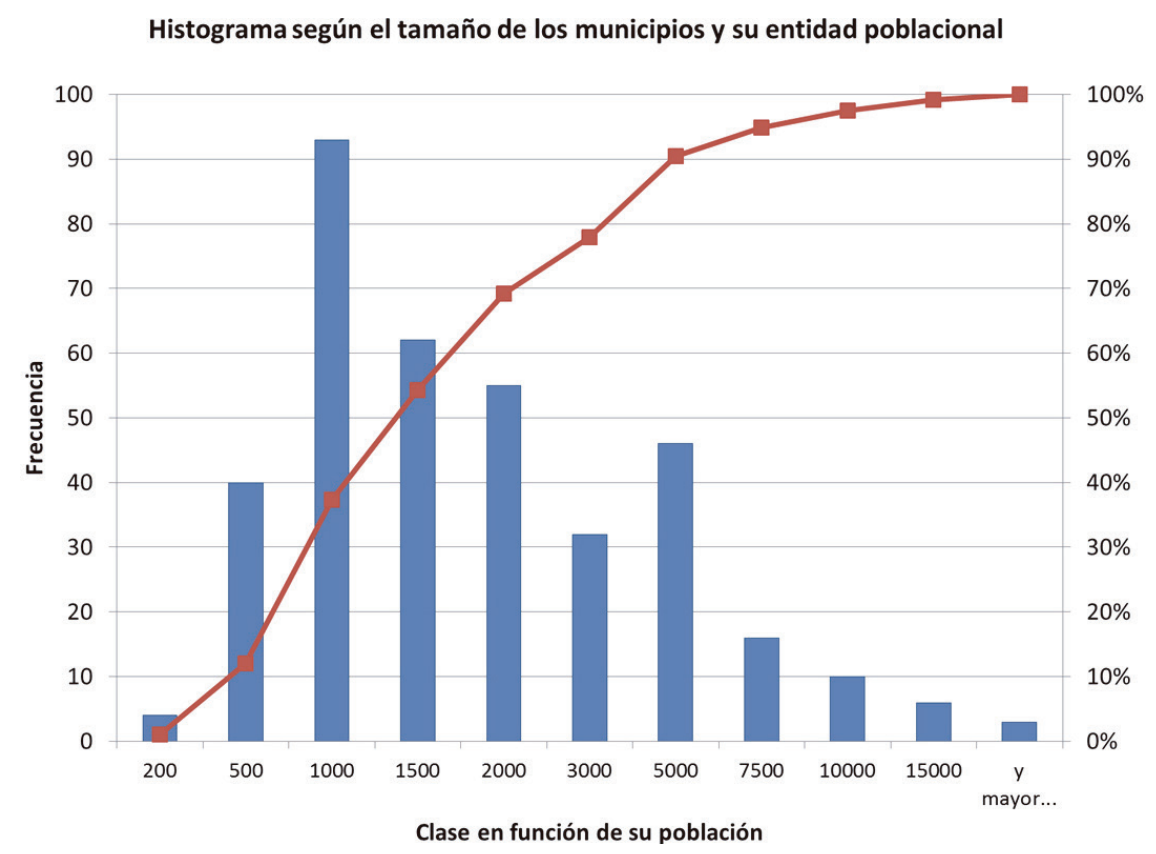

Gráfico 1. Grado de ruralidad de la población extremeña en 2016.

Fuente: elaboración propia

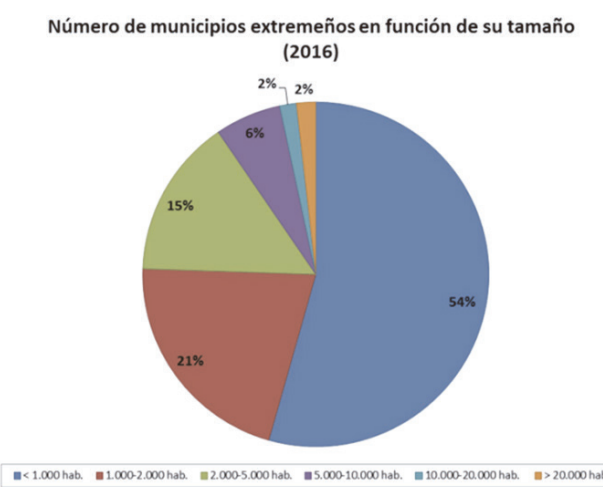

\begin{abstract}
Porcentaje de población en función del tamaño de los municipios extremeños (2016)
\end{abstract}

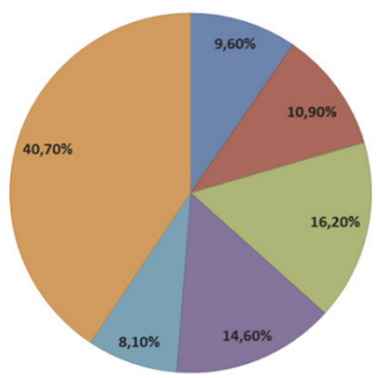

Gráfico 2. Comparativa entre numero municipios/entidad poblacional y tamaño, 2016.

Fuente: elaboración propia

Por tanto, según los datos del Instituto Nacional de Estadística (INE) de 31 de diciembre de 2016, Arroyo de la Luz cuenta con 5966 habitantes, repartidos de la siguiente manera. 
Tabla 1. Distribución de la población en Arroyo de la Luz y porcentaje de población analizada en el trabajo.

\begin{tabular}{|l|c|c|c|c|c|c|c|c|}
\cline { 2 - 8 } & Total & $\%$ & Hombres & $\%$ & Mujeres & $\%$ & $\begin{array}{c}\% \\
\text { población } \\
\text { encuestada }\end{array}$ & $\begin{array}{c}\% \\
\text { población } \\
\text { analizada } \\
\text { en base } \\
\text { de datos } \\
\text { biblioteca }\end{array}$ \\
\hline 0 a 5 años & 221 & $3,70 \%$ & 114 & $3,84 \%$ & 107 & $3,57 \%$ & $0 \%(0)$ & \multirow{2}{*}{$86 \%(284)$} \\
\hline 6 a 12 años & 332 & $5,56 \%$ & 173 & $5,82 \%$ & 159 & $5,31 \%$ & $15 \%(50)$ & \\
\hline 13 a 100 años & 5413 & $90,73 \%$ & 2684 & $90,34 \%$ & 2729 & $91,12 \%$ & & \\
\hline
\end{tabular}

Fuente: elaboración propia

A lo largo de estos últimos años ha descendido su natalidad que ha pasado de cincuenta niños nacidos en 2004 a veintitrés en 2011 (intervalos de comienzo y finalización de nuestro trabajo). No obstante, nuestro estudio ha incidido sobre el $100 \%$ de la población en edad escolar de manera directa o indirecta, como se podrá comprobar.

\subsection{Nacimientos/lectores infantiles de la biblioteca municipal}

A través del padrón municipal hemos obtenido las cifras oficiales de los habitantes nacidos entre el 1/01/ 2004 y el 31/12/2011. Hemos cruzado la información con la hoja de cálculo de la biblioteca municipal, que almacena los datos referentes a los libros, préstamos y socios, de manera que hemos obtenido el porcentaje de población que la frecuenta con asiduidad, tal como se registra en la siguiente tabla.

Tabla 2. Niños usuarios de la biblioteca, número y porcentaje de libros leídos.

\begin{tabular}{|c|c|c|c|c|c|}
\hline Año & Nacimientos & $\begin{array}{c}\text { Niños socios / \% } \\
\text { población }\end{array}$ & $\begin{array}{c}\mathbf{N}^{0} \text { socios } \\
\text { (niños/niñas) }\end{array}$ & $\begin{array}{l}\text { Libros } \\
\text { leídos }\end{array}$ & \% libros leídos \\
\hline \multirow{2}{*}{2004} & \multirow{2}{*}{50} & \multirow{2}{*}{$42(84 \%)$} & 19 & 0 & $0 \%$ \\
\hline & & & 23 & 0 & $0 \%$ \\
\hline \multirow{2}{*}{2005} & \multirow{2}{*}{50} & \multirow{2}{*}{$48(96 \%)$} & 31 & 3 & $75 \%$ \\
\hline & & & 17 & 1 & $25 \%$ \\
\hline \multirow{2}{*}{2006} & \multirow{2}{*}{35} & \multirow{2}{*}{$34(97 \%)$} & 16 & 22 & $48,89 \%$ \\
\hline & & & 18 & 23 & $51,11 \%$ \\
\hline \multirow{2}{*}{2007} & \multirow{2}{*}{52} & \multirow{2}{*}{$45(86 \%)$} & 19 & 49 & $37,69 \%$ \\
\hline & & & 26 & 81 & $62,31 \%$ \\
\hline \multirow{2}{*}{2008} & \multirow{2}{*}{43} & \multirow{2}{*}{$38(88 \%)$} & 26 & 61 & $27,98 \%$ \\
\hline & & & 12 & 157 & $72,02 \%$ \\
\hline
\end{tabular}




\begin{tabular}{|c|c|c|c|c|c|}
\hline Año & Nacimientos & $\begin{array}{c}\text { Niños socios / \% } \\
\text { población }\end{array}$ & $\begin{array}{c}\mathrm{N}^{0} \text { socios } \\
\text { (niños/niñas) }\end{array}$ & $\begin{array}{l}\text { Libros } \\
\text { leídos }\end{array}$ & \% libros leídos \\
\hline \multirow{2}{*}{2009} & \multirow{2}{*}{47} & \multirow{2}{*}{$36(76 \%)$} & 12 & 131 & $24,62 \%$ \\
\hline & & & 24 & 401 & $75,38 \%$ \\
\hline \multirow{2}{*}{2010} & \multirow{2}{*}{29} & \multirow{2}{*}{$26(89 \%)$} & 10 & 168 & $23,05 \%$ \\
\hline & & & 16 & 561 & $76,95 \%$ \\
\hline \multirow{2}{*}{2011} & \multirow{2}{*}{23} & \multirow{2}{*}{$15(65 \%)$} & 6 & 148 & $21,48 \%$ \\
\hline & & & 9 & 541 & $78,52 \%$ \\
\hline Total & 329 & $284(86 \%)$ & 284 & 2347 & \\
\hline
\end{tabular}

Fuente: elaboración propia

\section{Resultados de esta interrelación}

El número de niños que nacen y se hacen socios de la biblioteca municipal es muy elevado (gráfico 3). Podemos destacar como un $97,14 \%$ se inscribió en la biblioteca (16 niños, 47,06\%; 18 niñas, 52,94\%) en 2006, año con el mayor porcentaje. 2007 fue la anualidad que más nacimientos registró, cuando el censo aumentó en 52 personas, de las cuales el $86,54 \%$ se inscribió en la biblioteca (19 niños, 42,22\%; 26 niñas, $57,78 \%$ ), dejando 2007 como el cuarto año con más usuarios. El último de los años que estudiamos, 2011, tuvo un pequeño descenso en la natalidad y en los socios de la institución, con solo 15 inscritos.

\section{Relación entre los niños nacidos y los socios}

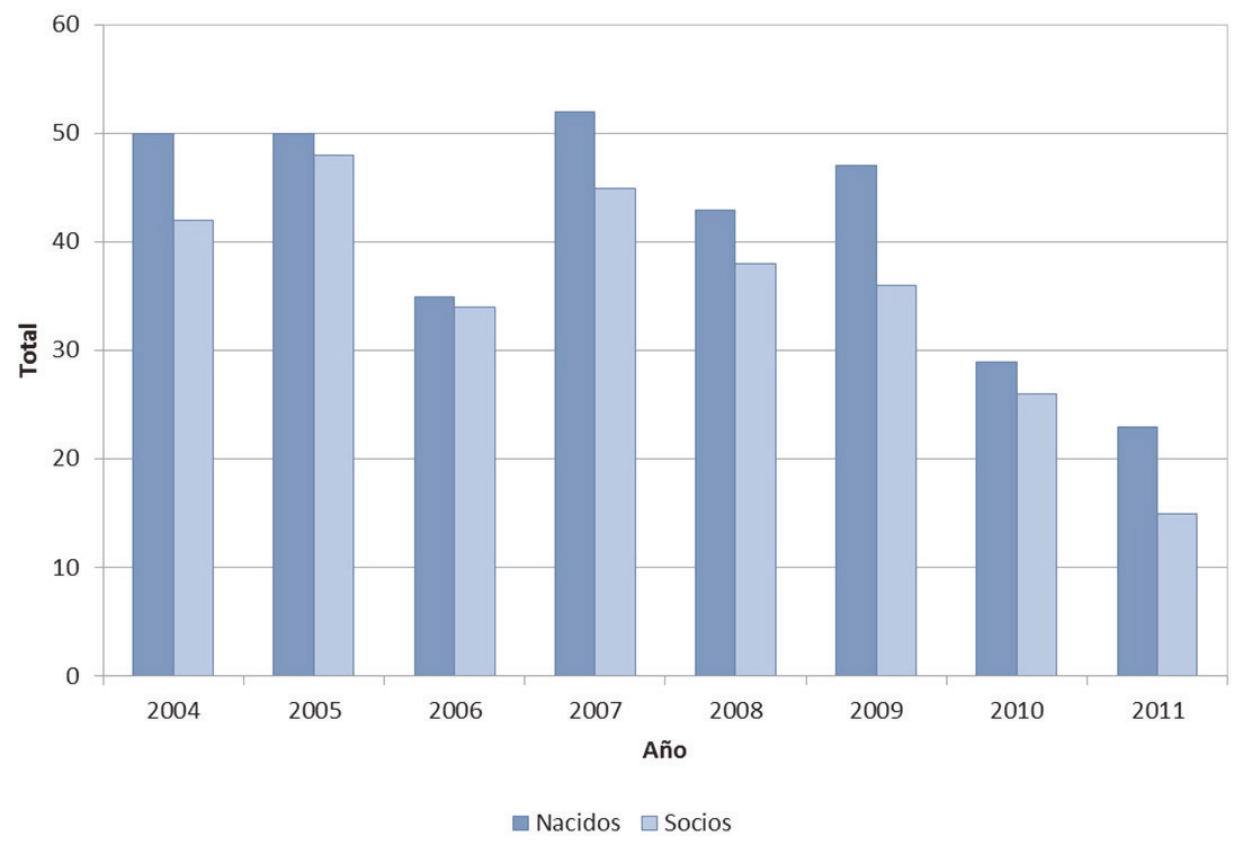

Gráfico 3. Nacimientos y usuarios de la Biblioteca Municipal de Arroyo de la Luz. Fuente: elaboración propia 
En lo tocante al sexo de los lectores, podemos ver esta información de manera más gráfica como sigue:

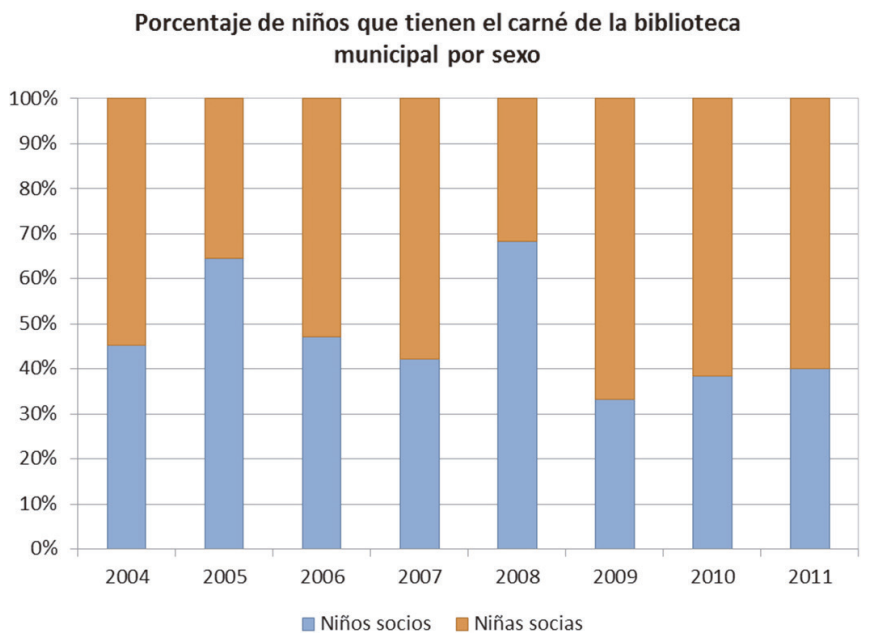

Gráfico 4. Porcentaje de niños que tienen el carné de la biblioteca municipal.

Fuente: elaboración propia

Parece claro que el perfil de usuario es femenino, tan solo en dos entradas es mayor el número de varones. Eso sucede en 2005, cuando nacieron 50 niños, de los cuales se inscribió el 96\% (31 niños y 17 niñas), así como en 2008, con el $88,37 \%$ (26 y 12 respectivamente). Resumiendo, es muy positivo que un alto porcentaje de neonatos se siga inscribiendo como lector de la biblioteca municipal (el 86\% de la población acotada), aunque haya descendido la natalidad.

\section{Gráficos de libros leídos entre 2004 y 2016 por los nacidos entre 2004 y 2011}

En el gráfico 5 encontramos el total de libros leídos por los 284 socios, 12909 libros. A simple vista podemos intuir que el préstamo aumenta, con un pico máximo en 2011 (1 833 obras) y un descenso en 2012 (228 libros), situación que repunta en 2014 (2 007 libros), cifra máxima en el histórico. De esta información concluimos que: en primer lugar, el punto álgido del hábito lector llega cuando tienen 6 años; por otro lado, vemos como, una vez que acceden a la Educación Primaria, el préstamo bibliotecario disminuye (véase como ejemplo el hecho de que en 2016 descendió en 743 libros respecto al año anterior).

\section{Libros leídos por los niños nacidos en 2004 en la biblioteca municipal}

En 2004 hubo cincuenta nacimientos, que en la actualidad están en el último curso de Educación Primaria. En el siguiente gráfico podemos confirmar con más evidencia la hipótesis de que es a los seis años cuando se muestra más interés por la lectura, pues, de los doce años que seriamos, es en 2010 cuando se registra un mayor dato, 729 libros leídos por los cuarenta y dos socios. Aunque hay un repunte a los 11 años, de manera que en 2016 se produce un descenso de 136 libros con respecto al año anterior. 


\section{Total de libros leídos por los niños nacidos entre 2004 y 2011}

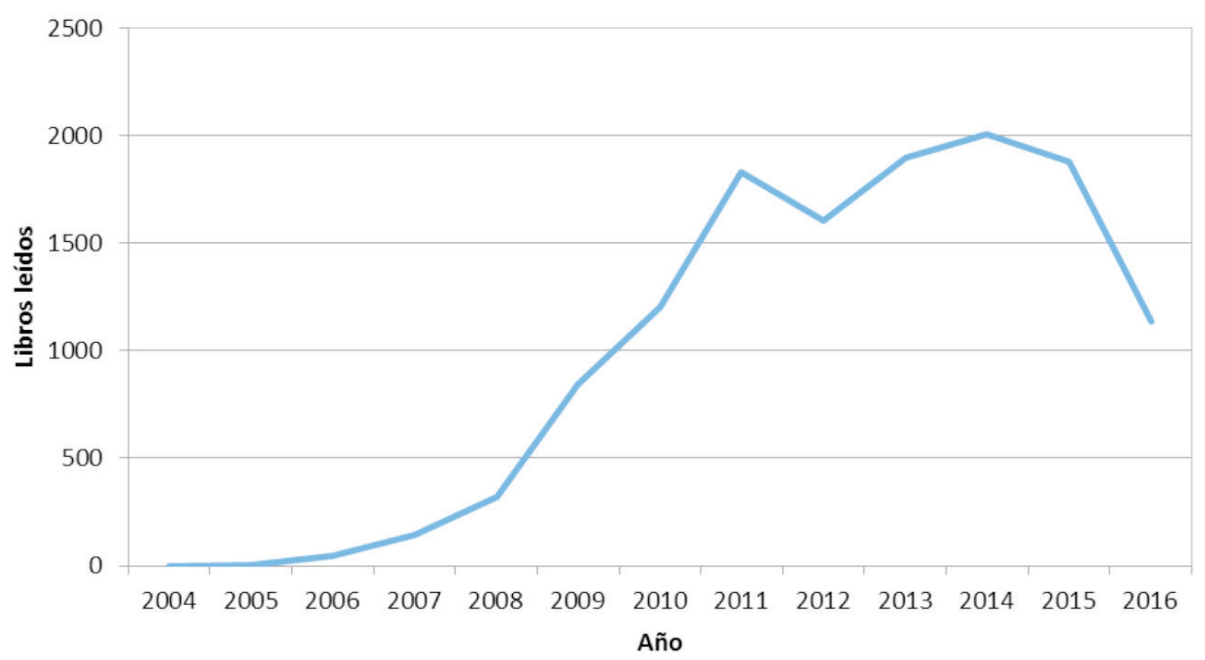

Gráfico 5. Total de libros leídos por los niños nacidos entre 2004 y 2011.

Fuente: elaboración propia

Total de libros leídos por los niños nacidos en 2004

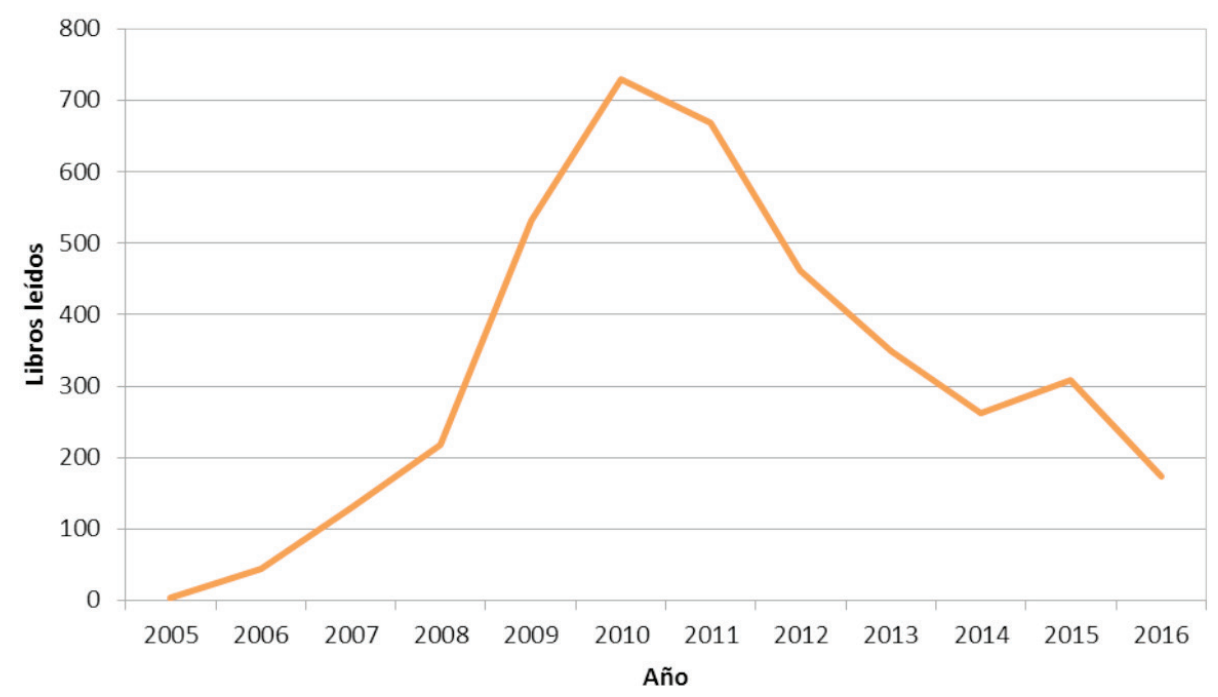

Gráfico 6. Total de libros leídos por los niños nacidos en 2004.

Fuente: elaboración propia

Por sexos también hay matices de interés, que se apuntaban ya en los estudios de carácter nacional y regional (MECD, 2015: 429; FGSR, 2007). Por medio del gráfico 7 constatamos que el perfil lector es claramente femenino, con una gran diferencia entre varones y mujeres. De este modo, tan solo hay un libro de margen entre ambos en 2006. Sin embargo, se registra un $88,29 \%$ de libros leídos por niñas, frente al 11,71 de niños en 2013. 


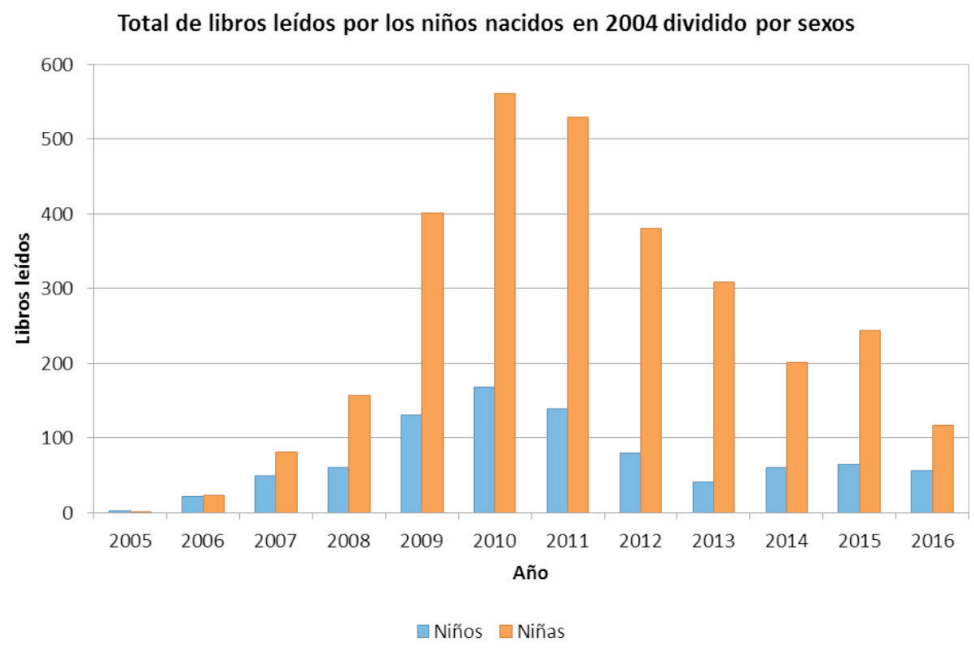

Gráfico 7. Total de libros leídos por los niños nacidos en 2004 dividido por sexos.

Fuente: elaboración propia

Debido a esta casuística quisimos realizar un nuevo gráfico en el que quedase constancia del porcentaje del perfil lector de este grupo. Vemos como el $77 \%$ fueron leídos por niñas (3 006 ejemplares), frente al 22,57 \% de los varones (876 libros).

\section{Porcentaje de libros leídos por los niños nacidos en 2004 dividido por sexos}

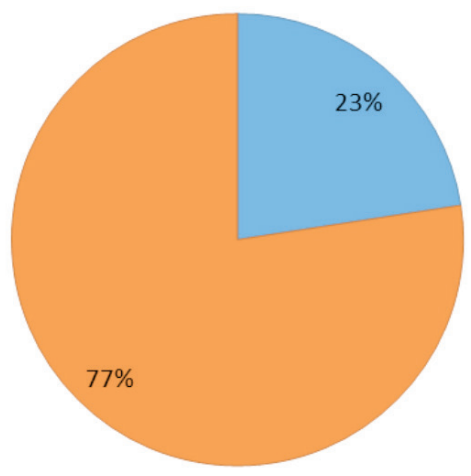

$\square$ Hombres $\square$ Mujeres

Gráfico 8. Porcentaje de libros leídos por los niños nacidos en 2004 dividido por sexos.

Fuente: elaboración propia

En cuanto al número de préstamos por cada sexo (número de libros prestados cada año), también son significativas las cifras, que casi doblan en el caso de las mujeres a las de los hombres. Este hecho les predispone inicialmente a una cultura libresca más frecuente. 
Tabla 3. Número de libros prestados por cada sexo entre los socios nacidos en 2004.

\begin{tabular}{|c|c|c|c|c|c|c|c|c|c|c|c|c|}
\hline $\begin{array}{c}\text { Año/ } \\
\text { Sexo }\end{array}$ & $\mathbf{2 0 0 5}$ & $\mathbf{2 0 0 6}$ & $\mathbf{2 0 0 7}$ & $\mathbf{2 0 0 8}$ & $\mathbf{2 0 0 9}$ & $\mathbf{2 0 1 0}$ & $\mathbf{2 0 1 1}$ & $\mathbf{2 0 1 2}$ & $\mathbf{2 0 1 3}$ & $\mathbf{2 0 1 4}$ & $\mathbf{2 0 1 5}$ & $\mathbf{2 0 1 6}$ \\
\hline Niños & 0,15 & 1,1 & 2,5 & 3,2 & 12,1 & 8,8 & 7,3 & 4,2 & 2,1 & 3,2 & 3,4 & 2,9 \\
\hline Niñas & 0,04 & 1 & 3,5 & 6,8 & 17,4 & 24,3 & 23 & 16,5 & 13,4 & 8,7 & 10,6 & 5 \\
\hline
\end{tabular}

Fuente: elaboración propia

\section{Libros leídos por los niños nacidos en 2010 en la biblioteca municipal}

Otra de las acotaciones se realizó con los nacidos en el 2010 (29 niños), para lo que contabilizamos sus lecturas hasta el 2016, último año con datos almacenados. Este nuevo apartado nos revela como es el antecedente lector de los niños que ahora han iniciado la Educación Primaria. En este periodo de tiempo (gráfico 9) no percibimos el conjunto global que ofrecíamos más arriba, sin embargo, se constatan cambios culturales entre la población de la localidad, como intentaremos mostrar a continuación.

Total de libros leídos por los niños nacidos en 2010

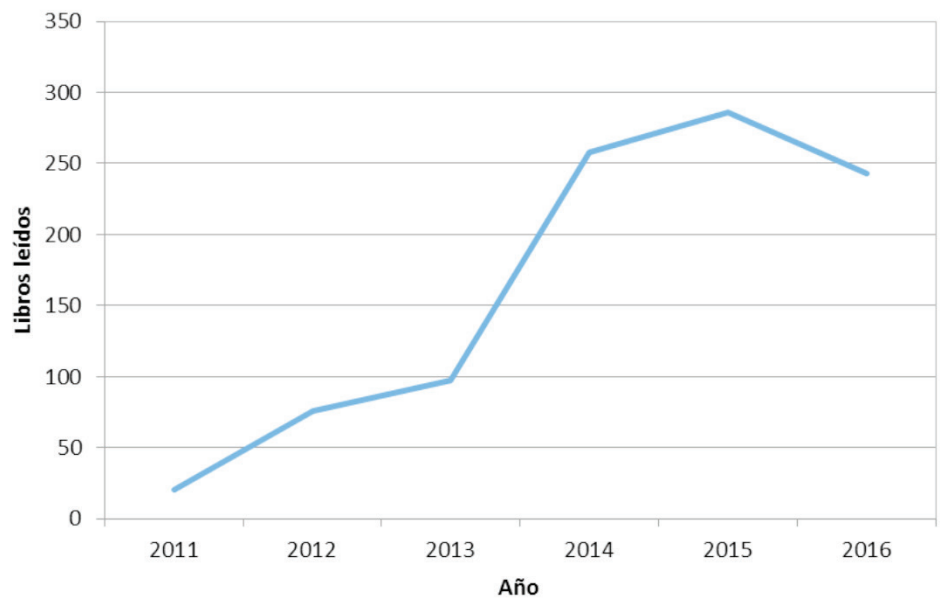

Gráfico 9. Total de libros leídos por los niños nacidos en 2010.

Fuente: elaboración propia

Al igual que sucedía en el epígrafe anterior, a la edad de 5 años (2015) es cuando se registra el punto más elevado de lecturas, con 286 libros. Otro de los aspectos que se repite es el descenso de la curva del gráfico un año después, con 43 libros menos. En esta ocasión contamos con 26 socios, los cuales han consultado 980 entradas. El perfil lector nuevamente es femenino, aunque en esta ocasión la diferencia no es tan acuciada. El mayor distanciamiento se produce en 2013, cuando se registró un total de 97 préstamos: el 69,07\% fue realizado por niñas (67 libros); frente al 30,93 de niños (30 títulos). Resumiendo, se leyeron un total de 980 obras en 2010: el 58,98\% (578) por niñas, frente al 41,02\% (402) por niños. 
Total de libros leídos por los niños nacidos en $\mathbf{2 0 1 0}$ dividido por sexos

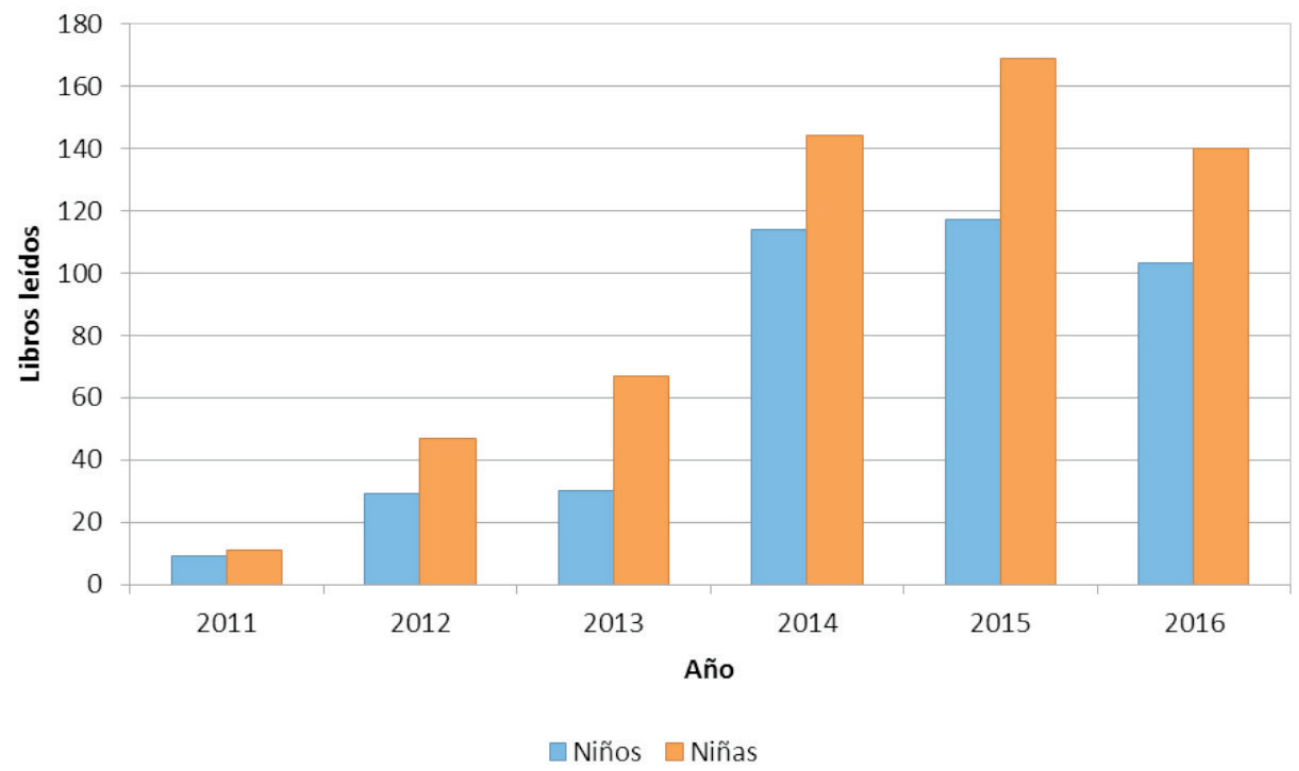

Gráfico 10. Total de libros leídos por los niños nacidos en 2010 dividido por sexos.

Fuente: elaboración propia

En cuanto al número de libros leídos por cada sexo anualmente, nos llama la atención el hecho de que los niños tengan un promedio mayor que las niñas, lo cual indica que se ha invertido la tendencia seis años después.

Tabla 4. Número de libros prestados por cada sexo entre los socios nacidos en 2010.

\begin{tabular}{|l|c|c|c|c|c|c|}
\hline Año/Sexo & $\mathbf{2 0 1 1}$ & $\mathbf{2 0 1 2}$ & $\mathbf{2 0 1 3}$ & $\mathbf{2 0 1 4}$ & $\mathbf{2 0 1 5}$ & $\mathbf{2 0 1 6}$ \\
\hline Niños & 0,6 & 2,9 & 4,1 & 9 & 10,5 & 8,7 \\
\hline Niñas & 0,9 & 2,9 & 3 & 11,4 & 11,7 & 10,3 \\
\hline
\end{tabular}

Fuente: elaboración propia

\section{Encuesta del alumnado de educación primaria}

como fuente de contraste realizamos un trabajo de encuestas entre los alumnos de Educación Primaria para saber qué tipo de libros les gusta leer, si pasan tiempo en la biblioteca, sus preferencias literarias..., según se aprecia en la Imagen 1 incluida más arriba, cuyos resultados hemos pasado a información gráfica. Estos reflejan los datos obtenidos en un total de cincuenta encuestas (15\% de esa población). De esta manera podemos observar un ciclo de edad, su opinión sobre la lectura y las fluctuaciones que se van produciendo. Las encuestas se agrupan de la siguiente manera: 
Tabla 5. Distribución de las encuestas realizadas.

\begin{tabular}{|l|c|c|c|}
\hline Grupo de edades & $\mathbf{N}^{\mathbf{0}}$ de encuestas & Niños & Niñas \\
\hline De 6 a 7 años & 15 & 6 & 9 \\
\hline De 8 a 9 años & 13 & 7 & 6 \\
\hline De 10 a 12 años & 22 & 11 & 11 \\
\hline Totales & 50 & 24 & 26 \\
$(15 \%$ de la población $)$ & $(8,36 \%$ de la población $)$ & $(9,77 \%$ de la población $)$ \\
\hline
\end{tabular}

Fuente: elaboración propia

\section{Análisis de los gráficos resultantes}

La primera pregunta que realizamos (gráfico 11) demuestra que un amplio porcentaje de niños entre los 6 y los 12 años tienen buena predisposición hacia la lectura.

\section{Gusto por la lectura de los escolares de Educación Primaria}

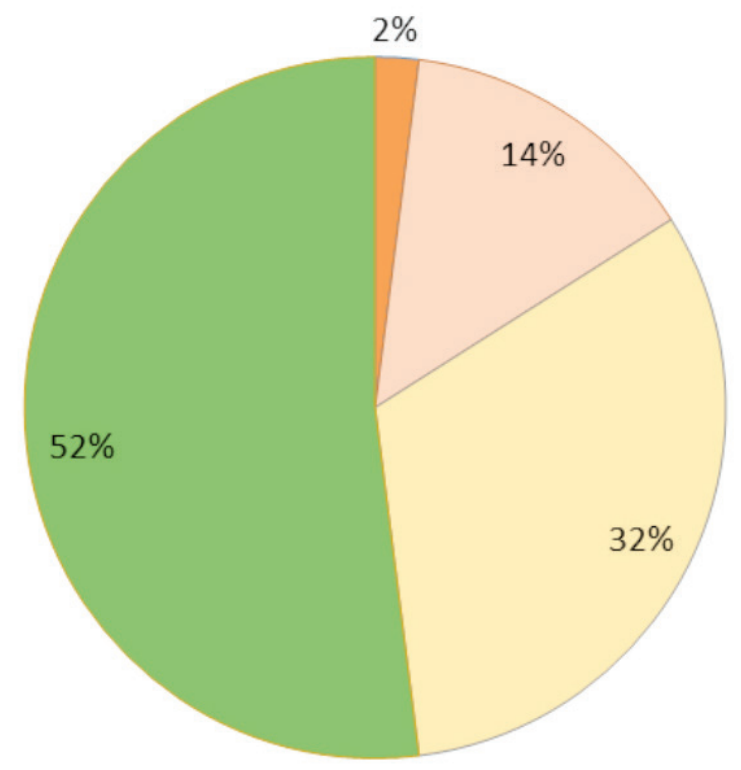
a) Nada
b) Poco
c) Bastante
d) Mucho

Gráfico 11. Representación gráfica de la pregunta ¿Te gusta leer?

Fuente: elaboración propia

Podemos apreciar que un alto porcentaje de los niños nacidos entre el 2004 y 2011 entiende lo importante que es la lectura para su formación (gráfico 12) y dedica su tiempo libre a esta actividad. 


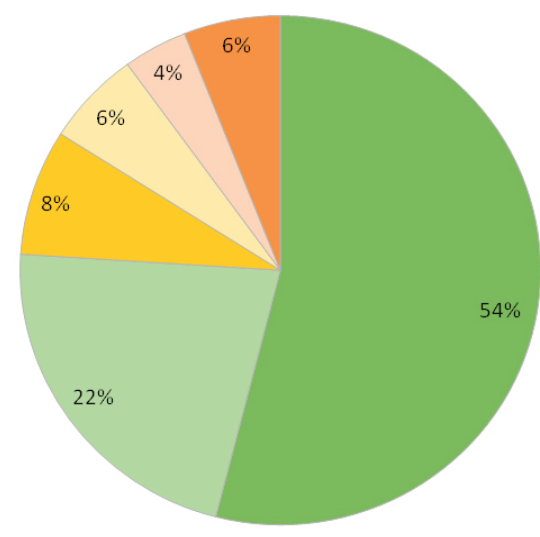

घa) Todos o casi todos los días $\square$ b) 1 o 2 veces por semana

$\square$ d) Alguna vez al trimestre $\square$ e) Casi nunca

c) Alguna vez al mes

in) Nunca

Gráfico 12 Representación gráfica de la pregunta ¿Sueles leer libros en tu tiempo libre?

Fuente: elaboración propia

Otro de los puntos que nos interesaba representar (gráfico 13) es el número de libros leídos en un año, debido a que se les ofrece un variado plan lector a lo largo de la Educación Primaria, más o menos obligatorio, que mostramos a continuación.

\section{Libros leídos en un año por niños de Educación Primaria}

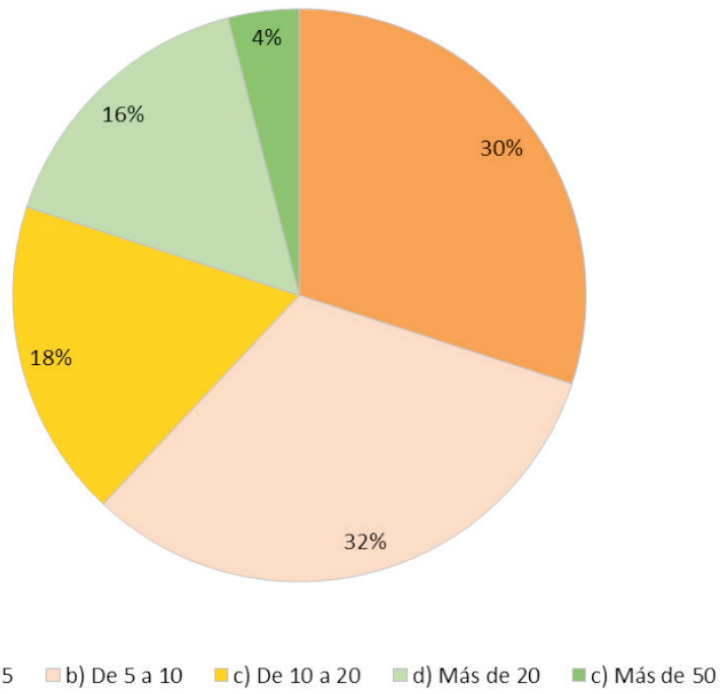

Gráfico 13. Representación gráfica de la pregunta ¿Cuántos libros has leído aproximadamente en un año? Fuente: elaboración propia 
Otra cuestión interesante era conocer el margen de tiempo que transcurre desde su última lectura. Nos sorprende el alto porcentaje que respondieron c) Hace menos de un mes, 43 de los 50 encuestados decían haber leído un libro en un corto periodo de tiempo, frente a siete que lo habían hecho con una diferencia de un mes.

Si observamos con detenimiento el gráfico 14 apreciamos que el 16\% (8) reconoce que cuando lo hace es por obligación, mientras que el $46 \%$ (23), por placer o recomendación. La principal diferencia entre la obligatoriedad o la recomendación estriba en el hecho de ser un acto impuesto por los docentes y requisito imprescindible asociado a la evaluación escolar y, por tanto, a la calificación final de las asignaturas. En ningún caso se entendía como una recomendación entre el grupo de iguales, sino desde la figura del docente.

\section{Motivaciones para la lectura de los niños de Educación Primaria}

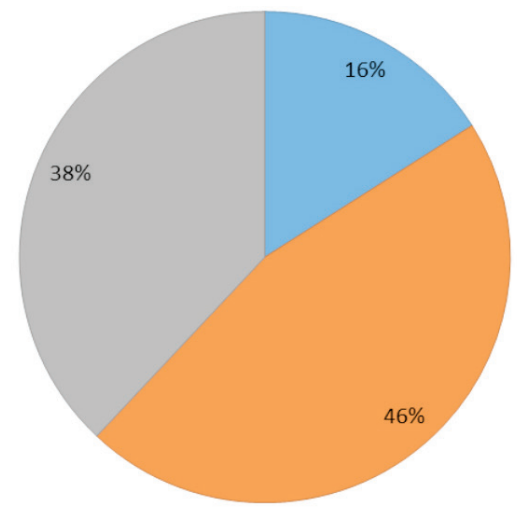

a) Por obligación

b) Porque me gusta y me lo han recomendado

$\square c)$ Por elección propia, porque me apetece

Gráfico 14. Representación gráfica de la pregunta ¿Lees por placer o por obligación?

Fuente: elaboración propia

También quisimos hacer constar la respuesta de aquellos que en la cuestión anterior afirmaron leer por obligación. Así, el porcentaje establecido es de 10 niños, de los cuales un $30 \%$ contestó que cuando leía un libro era porque los profesores le obligaban, mientras que el otro $70 \%$ confirmaba que los padres les fuerzan a leer. Aunque la imposición es idéntica para todo el grupo, la percepción de realizar esta actividad de manera forzada es minoritaria entre los encuestados, como puede apreciarse, lo que viene a constatar que no se produce tensión ni estrés en los escolares por este motivo. Efecto que se refuerza con similares valores en la lectura en el tiempo de ocio, si bien, en estos casos la imposición es de carácter familiar.

Otro apartado correlaciona el tiempo de ocio y la lectura (gráfico 15): un 54\% (27) reconoce leer en vacaciones, frente al $8,16 \%$, que asume leer en ese periodo de manera obligada. En el medio encontramos un 30\% (15) que podríamos sumar a los primeros, pues también leen en este tiempo vacacional, aunque lo han hecho porque les gusta o bien porque el libro que están leyendo ha sido una recomendación. 


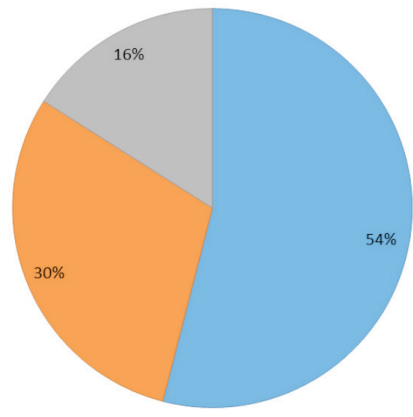

Si, por eleccion propia, porque me apetece

b) Si, porque me gusta, aunque me lo han recomer

Por obligacion

Gráfico 15. Representación gráfica de la pregunta ¿Lees en vacaciones?

Fuente: elaboración propia

Otra de las cuestiones que nos interesaba es si sentían que en su círculo más cercano (familia, amigos o conocidos) se regalan libros, si perciben que las personas próximas tienen esa misma pasión y se la inculcan desde pequeños (gráfico 16). Un $64 \%$ veía como en cualquier fecha importante (cumpleaños, Reyes Magos, etcétera) recibía como obsequio un libro. Junto a ellos podrían estar el 20\% (10) que contestó que era frecuente y de manera mínima. Muy cerca se encuentra el 16\% (8), que asume que nunca lo ha recibido.

\section{ibros como regalo para los niños de Educación Prin}

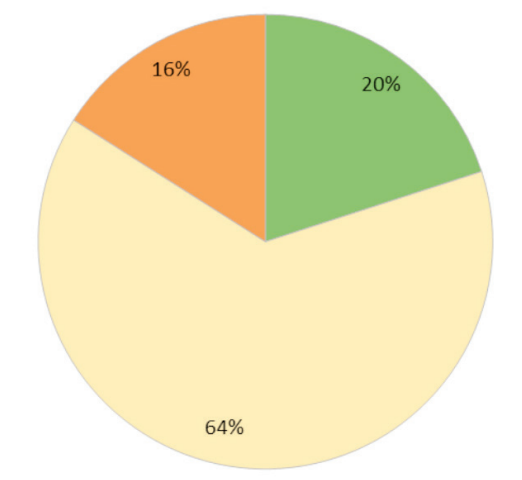

ma) Frecuentemente

$\square$ b) Algunas veces $\quad \square$ c) Nunca

Gráfico 16. Representación gráfica de la pregunta ¿Tu familia o amigos suelen regalarte libros en tus cumpleaños, reyes? Fuente: elaboración propia

Respecto a cómo llegan los libros a sus manos (gráfico 17), los porcentajes están bastante igualados, salvo por la opción a) Me lo prestaron, que recoge el 8\% (4), que comentan como el libro que están leyendo fue a través de un préstamo. Retomando 
el tema anterior, el libro como regalo cobra protagonismo: el 34\% (17) marcó esta opción. Muy de cerca le sigue el 32\%, en cuyo caso el libro fue un préstamo del colegio, algo en lo que nos centraremos más adelante. Para finalizar, 13 acudieron a la biblioteca para recoger su última lectura.

Procedencia o adquisión del último libro leído en niños de Primaria

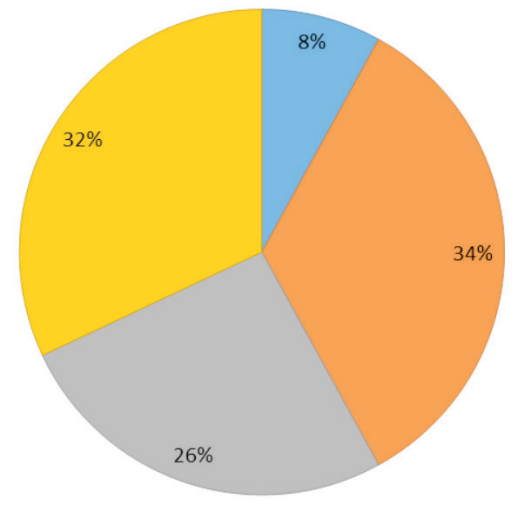

$\square$ a) Me lo prestaron $\square$ b) Me lo regalaron $\square$ c) Préstamo de la biblioteca $\square$ d) Préstamo del colegio

Gráfico 17. Representación gráfica de la pregunta ¿Cómo ha llegado a tus manos el último libro que has leído o estás leyendo? Fuente: elaboración propia

Teníamos la necesidad de descubrir si los niños de Educación Primaria recurrían a las bibliotecas para encontrar un libro acorde a su gusto literario. De los cincuenta encuestados, un 94\% (47) reconocía que en el último año había visitado una biblioteca, frente al 6\% (3). Además, se les preguntaba si la biblioteca que han visitado es pública o escolar. En este punto varios alumnos contestaron haber ido a ambas. Aun así, los resultados de la encuesta muestran como los porcentajes son muy igualados. Mientras que el 57\% (47) confirma haber acudido a una biblioteca pública, el 43\% (35) también lo había hecho a una biblioteca escolar.

En el gráfico 18 registramos el tiempo que pasa entre sus lecturas, si el hábito es constante o, por el contrario, algo anecdótico. Finalmente, se constata que son lectores asiduos.

Igualmente, queríamos investigar los gustos literarios de los niños de Educación Primaria (gráfico 19). Las opciones propuestas fueron muy variadas y engloban todas aquellas temáticas que llaman su atención. La preferencia de los niños de 6-12 años es clara: 37 son los votos que recibió Aventura y Acción, una de las pocas que gustaba tanto a niños como niñas. En segundo lugar, 24 niños eligieron los libros de animales. Otros géneros están más parejos, como sucede con la literatura de Viajes, Deportes y Arte y Música, las dos últimas elegidas por un 8,56\% (16), mientras que Viajes tiene un porcentaje de 9,09\% (17). Esto mismo sucede con las obras de Terror y Cuento de Hadas, ambas con un 7,49\% (14). Aquí, sin embargo, apreciamos los opuesto a la temática de Aventura y Acción, esta opción es la menos votada. Como preferencias minoritarias aparecen las novelas de Humor, 6,95\% (13); Amor y Cómic, 5,88\% (11); Coches, 4,28\% (8) y Fábulas, 3,21\% (6). 


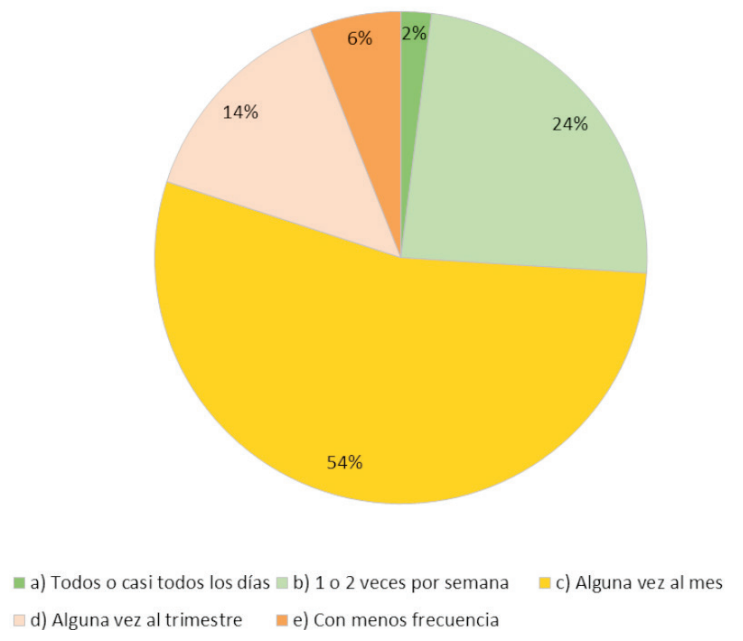

Gráfico 18. Representación gráfica de la pregunta ¿Con qué frecuencia visitas las bibliotecas? Fuente: elaboración propia

\section{Temáticas preferentes para los niños de Educación Primaria}

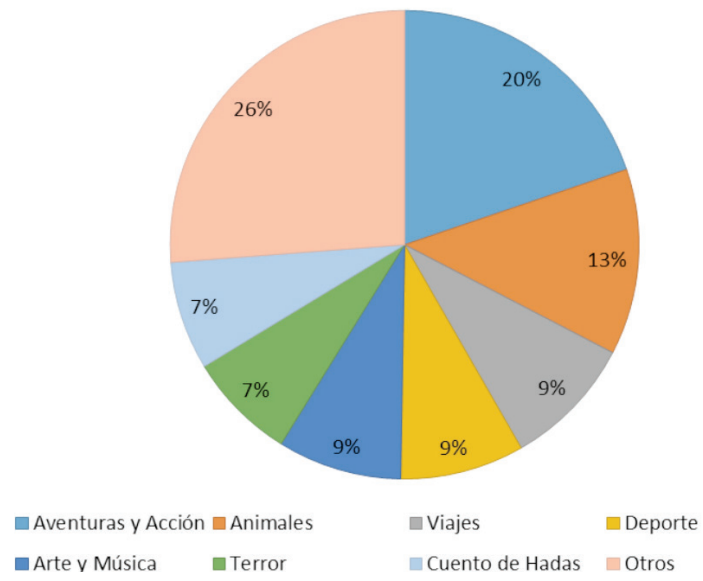

Gráfico 19. Representación gráfica de la pregunta "Preferencia de libros". Fuente: elaboración propia

En último lugar, con la intención de conocer que otras actividades realizan en su tiempo libre, descubrimos que prefieren jugar con sus amigos, si bien, la segunda opción más votada fue la lectura.

En último término, apreciamos que los escolares entienden la importancia de la lectura literaria para el aprendizaje y la comunicación (gráfico 20), lo que viene a demostrar que la percepción del acto lector es positiva en la mayoría de los casos. Este sentimiento predomina sobre otros más placenteros y lúdicos. 


\section{La utilidad de la lectura para un niño de Educación Primaria}

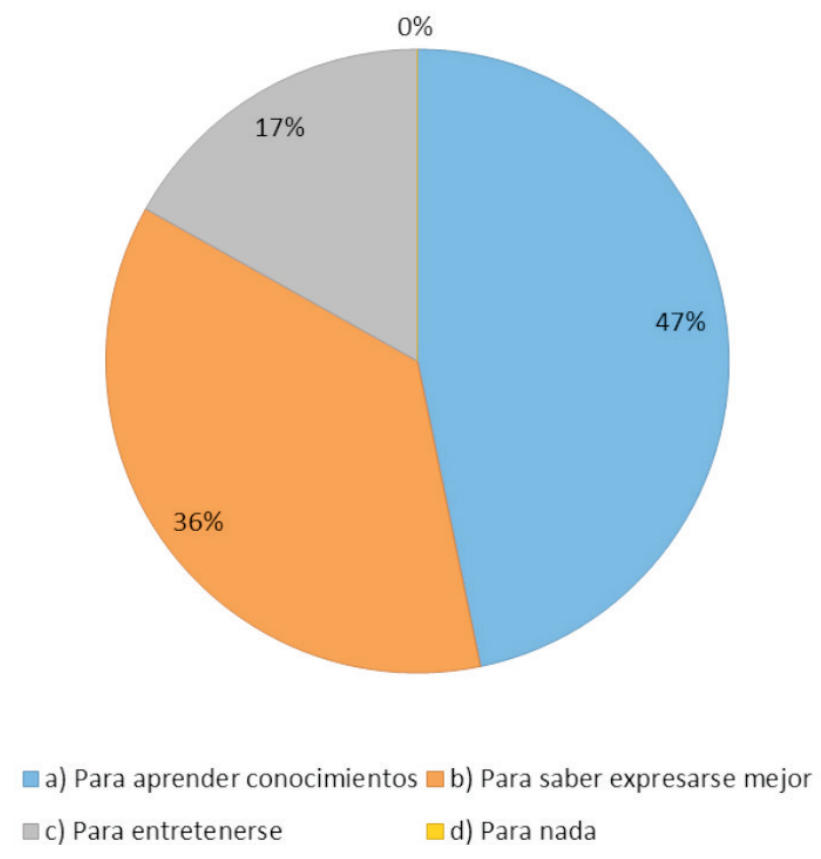

Gráfico 20. Representación gráfica de la pregunta ¿Para qué sirve la lectura?

Fuente: elaboración propia

\section{Conclusiones}

Una vez llegados a este punto podemos concluir que las lecturas realizadas por los niños en sus primeros años de vida son bastante elevadas, con un promedio de más 10 libros al año de préstamos bibliotecario. Este temprano acercamiento al libro impreso muy posiblemente les hace ser conscientes de la importancia de la lectura para la adquisición de nuevos conocimientos $(72 \%)$.

Igualmente, aunque con fluctuaciones que necesitarían de más variables de estudio, como son los aspectos económicos (no podemos olvidar que el descenso de la natalidad y de la frecuencia lectora disminuye en los años más acuciados de la crisis económica), las niñas viven con más proximidad la cultura libresca. Sirva de ejemplo como las nacidas en 2004 seis años después registran un total de 561 libros leídos frente a los 168 de los niños, hecho que se repite en 2011 cuando las niñas leyeron 391 libros más que los varones.

Otro hecho que quisiéramos resaltar es la implicación familiar o del contexto cercano del niño en la adquisición del hábito lector. Véase como el mayor número de obras prestadas por año se produce en los primeros años de vida, en los que los tutores de los infantes realizan esos préstamos en la biblioteca municipal y que, sin embargo, disminuye notablemente tras la incorporación al sistema educativo, en especial a la Educación Primaria. Muy posiblemente podemos vincular este hecho objetivo con que el $52 \%$ de los encuestados reconozca que le gusta leer, o que el $54 \%$ lea todos o casi todos los días, mientras que tan solo un $2 \%$ asume que 
no lee en su tiempo libre. Mediante los gráficos pudimos descubrir como el hábito lector va en disminución conforme la edad de los niños aumenta. El punto álgido del hábito lector se produce a los 5-6 años, pues si miramos más concretamente lo que ocurre en el primer año que estudiamos (2004), apreciamos que el máximo de libros leídos tiene lugar en 2010, cuando se alcanza un total de 729 libros. A partir de ahí vemos como la lectura comienza a disminuir hasta llegar en 2014 a los 262 libros.

De otro lado, cuando los niños ya han adquirido los rudimentos lectores tienen claras sus preferencias respecto a los géneros literarios y sus gustos estéticos, corroborados también en otros estudios más generales. Así, destaca la temática de "Aventuras y Acción", seguidos de los libros de de "Animales" frente a las obras que consideradas "Fábulas" o que hablan de "Coches" que son las menos elegidas.

Si bien casi el $86 \%$ de los niños acude con asiduidad en sus primeros años de vida a la biblioteca municipal, de ahí la importancia del servicio que prestan estas instituciones en el ámbito rural al mundo cultural extremeño, cuando se inicia el sistema educativo reglado, lo hacen casi en el mismo porcentaje a la biblioteca escolar $(42,68 \%)$ que a la biblioteca pública (47\%). Tanto a una como a otra, más de la mitad (54\%) reconoce que acude a ellas "Alguna vez al mes", muy de cerca con un $24 \%$ se quedan aquellos que dicen hacerlo una o dos veces por semana. Cabe señalar que este descenso lector en la biblioteca municipal se debe a que comparte el mismo grupo de lectores con las bibliotecas escolares, de manera que florece un nuevo componente antes desconocido para ello. A esto debe sumarse la aparición de nuevas materias escolares que requerirán de tiempo, junto con actividades de ocio en la localidad (talles infantiles, actividades extraescolares del contexto educativo) que comienzan en estos años.

Quizás, gracias a las políticas tempranas de hábitos lectores fomentadas por los servicios de biblioteca, comprendamos que los niños de Educación Primaria dedican buena parte de su tiempo libre (el 29,13\% de los encuestado) a la lectura. Y, por otro lado, al menos en esta edad, apenas un $8,74 \%$ y un $4,85 \%$, respectivamente, reconoce dedicar su tiempo libre a la ver la televisión o a jugar con videojuegos. Llama también poderosamente la atención que apenas un 2,91\% tenga entre sus preferencias la búsqueda de información en internet, lo que viene a confirmar la posición de privilegio de las obras en papel frente a los formatos digitales hasta la fecha.

En la parte cuantitativa, es necesario mencionar la diferencia de libros leídos según el sexo. Por ejemplo, que en 2004, el $77 \%$ lo de préstamos fuera realizado por niñas, aspecto que se reitera en muchos años del trabajo, nos debe hacer plantearnos la necesidad de realizar campañas de sensibilización que atraigan el interés de los varones hacia el libro, ya que supone un distanciamiento importante que tendrá consecuencias en su desarrollo académico posterior.

Igual sucede en lo tocante a su acceso a la biblioteca, donde el porcentaje de socias en los años estudiados siempre es más elevado, con valores que van desde el 54,76\% de las niñas nacidas en 2004 hasta el $61,54 \%$ de 2010 , frente al $45 \%$ y $38,46 \%$ de los niños nacidos en esos mismos años. De este modo, la interrelación vuelve a poner en lugar destacado a las mujeres frente a los varones, lo que nos ayuda a entender como su cultura libresca y académica irá de la mano de la lectura impresa con más frecuencia en las niñas. 


\section{Agradecimientos}

Trabajo incluido en las actividades del Grupo de Investigación "LIJ" (SEJ036) y "DESOSTE" (SEJ024) del Catálogo de grupos de la Junta de Extremadura, dentro del "Proyecto de Investigación sobre los hábitos de lectura en Extremadura", coordinado por José Soto Vázquez, Referencia 037/17 del Plan de Fomento de la Lectura. Nuestro agradecimiento al Ayuntamiento de Arroyo de la Luz por su disponibilidad y ofrecimiento de los datos, sin cuya ayuda no hubiera sido posible la realización de este trabajo.

\section{Bibliografía}

Atwood, B. (1984): Cómo desarrollar la lectura crítica, Barcelona, Ed.CEAC.

Bernabeu, Natalia et al. [Coords.] (2011): Alfabetización mediática y competencias básicas, Madrid, MECD.

Bernstein, B. (1975): Class, codes and control, London, Routledge and Kegan.

Cerrillo, Pedro C. y J. García Padrino [eds.] (1996): Hábitos lectores y animación a la lectu$r a$, Murcia, Compabell.

Cerrillo, Pedro C. (2005): “Lectura y sociedad del conocimiento", en Revista de Educación, núm. extraordinario, 53-61.

Cervera, Juan (1988): La literatura infantil en la Educación Básica, Madrid, Cincel-Kapelusz.

Colomer, Teresa y A. Camps (1996): Enseñar a leer, enseñar a comprender, Madrid, Celeste.

DoCampo, X. P. (2002): “Leer, ¿Para qué?”, Hablemos de leer, Madrid, Anaya.

Fundación Germán Sánchez Ruipérez (2007): Hábitos de lectura y compra de libros en Extremadura (14 a 24 años).

García, J. (2011): Plan de trabajo y autoevaluación de la biblioteca escolar, Documento de Referencia para bibliotecas escolares DR1/BECREA, Sevilla, Junta de Andalucía, Consejería de Educación.

Gil, Javier (2009): "Hábitos y actitudes de las familias hacia la lectura y competencias básicas del alumnado", en Revista de Educación, 350, 301-322.

Godoy, Ana Aurora (2012): "La lectura en educación primaria", Revista internacional de audición y lenguaje, logopedia, apoyo a la integración y multiculturalidad, en Vol. 1, $\mathrm{n}^{\mathrm{o}}$ 4, 59-66.

Instituto Nacional de Estadística (2017): Fondo documental del Instituto Nacional de Estadística.

Lomas, Carmen (2002): Cómo hacer hijos lectores, Madrid, Palabras, S.L.

Martín, Gustavo (2012): "Una casa de palabras", en El País.

Martos, Eloy y M. Campos (Coords.) (2013): Diccionario de nuevas formas de lectura y escritura, Madrid, Santillana.

Mendoza, Antonio (1998): Tú lector, Barcelona, Octaedro.

Millán, José Antonio [Coord.] (2016): La lectura en España. Informe 2017, Madrid, Federación de Gremios de Editores de España.

MECD (2011): Marco de referencia para las bibliotecas escolares, Madrid, Subdirección General de Documentación y Publicaciones.

MECD (2015): “Orden ECD/65/2015, de 21 de enero, por la que se describen las relaciones entre las competencias, los contenidos y los criterios de evaluación de la educación primaria, la educación secundaria obligatoria y el bachillerato", en BOE, 25, 6986-7003. 
MECD (2015): Encuesta de Hábitos y Prácticas Culturales en España. 2014- 2015, Madrid, Ministerio de Educación, Cultura y Deporte.

Molina, Elvira (2015): “La mejora de la competencia en comunicación lingüística: 'Alehop' y la experiencia en un contexto desfavorecido", en Participación Educativa, Vol. 4, n 6, 91-96.

Muñoz, José Manuel y A. Hernández (2011): “Hábitos lectores de los alumnos de la ESO en la provincia de Salamanca. ¿Son el género y el entorno factores diferenciales?”, en Revista de Educación, 354, 605-628.

Nieto, Ana y J. L. Gurría (2005): “Análisis de la población de los programas de desarrollo rural en Extremadura mediante sistemas de información geográfica”, en BIBLID, 36, 479-495.

Olaziregi, Mari Jose (2000): “Aproximación sociológica a los hábitos de lectura de la juventud vasca", en BIBLID, 18, 79-93.

Patte, Geneviève (2008): Déjenlos leer. Los niños y las bibliotecas, México, Fondo de Cultura Económica

Pennac, Daniel (1993): Como una novela, Joaquín Jordá (trad.), Barcelona, Anagrama.

Peronard, Marianne (2007): "Lectura en papel y en pantalla de computador", en Revista Signos, 40(63), 179-195.

Real Academia Española (2010): Ortografía de la lengua española, Madrid, España.

Rubio, Esther (2007): “Aprendizaje a la largo de la vida. Vivir y trabajar en una Europa del conocimiento", en Participacion Educativa, 6, 14-29.

Schmitt, M. C. y J. F. Baumann (1990): "Metacomprehension during basal reading instruction: Do teachers promote it?", en Reading Research and Instruction, 29(3), 1-13.

Serna, Maite; A. Rodríguez y X. Etxaniz (2017): “Biblioteca escolar y hábitos lectores en Educación Primaria", en Ocnos, 16 (1), 18-49.

Villegas, Claudia (2010): "Análisis del proceso de la adquisición de nuevo vocabulario a través del tratamiento de la práctica de lectura", en Tiempo de Educar, vol. 11, núm. 21, 9-30.

Viñao, Antonio (2002): "La enseñanza de la lectura y la escritura: análisis socio-histórico", en Anales de documentación, no 5, 345-359.

\section{Espacios web}

Asociación de las Cámaras del libro en España (2016). Comercio exterior del libro. 2015: http://federacioneditores.org/img/documentos/Comercio_Exterior_2015.pdf [09/12/2016].

MECD (2013-2014): Nube de lágrimas. Club de lecturas en la nube; E-book +18 -40. Los lectores y los libros electrónicos; y Hábitos de lectura y compra de libros en España (2012): http://www.mecd.gob.es/cultura-mecd/areas-cultura/libro/mc/observatoriolect/ redirige/estudios-e-informes/elaborados-por-otras-entidades-con-la-colaboracion-delministerio/lectura.html [09/12/2016].

MECD (2014): La participación de las familias en la educación escolar: http://www.mecd. gob.es/dctm/cee/publicaciones/estudioparticipacion/estudioparticipacion. pdf?documentId=0901e72b81b45e35 [09/12/2016].

MECD (2016): El sector del libro en España (2013-2015): http:/www.mecd.gob.es/dms/ $\mathrm{mecd} /$ cultura-mecd/areas-cultura/libro/mc/observatoriolect/redirige/estudios-e-informes/ elaborados-por-el-observatoriolect/sector-libro-abril2015/sector-libro-abril2015.pdf [09/12/2016]. 
Morales, Pedro (2012): “Tamaño necesario de la muestra: ¿Cuántos sujetos necesitamos?”, Universidad Pontificia de Comillas, Madrid: http://s3.amazonaws.com/academia.edu.documents/31398804/Tamanomuestra-INTERESANTE.pdf?AWSAccessKeyId=AKIAIW OWYYGZ2Y53UL3A\&Expires $=1497524615 \&$ Signature $=$ CCoCKc89SIhAZzAuEnpxa U A d 0 y $0 \% 3$ D \& res p on s e - content - dis p o s ition=in 1 in e $\% 3$ B \% 20 filename\%3DTamanomuestra-INTERESANTE.pdf [15/06/2017].

Unesco (2000): Manifiesto UNESCO/IFLA sobre la Biblioteca Escolar. http://www.unesco. org/webworld/libraries/manifestos/school_manifesto_es.html [15/09/2016]. 